\title{
PENGARUH METODE BERMAIN BOLA TANGAN DAN LEMPAR TANGKAP BOLA TERHADAP EFEKTIFITAS PEMBELAJARAN PASSING ATAS BOLAVOLI PADA KELAS XII TPHP SMK PUTRA WILIS KECAMATAN SENDANG KABUPATEN TULUNGAGUNG
}

\author{
Ridwan Hanafi ${ }^{1}$, Ardhi Mardiyanto Indra Purnomo ${ }^{2}$, Weda $^{3}$ \\ Penjaskesrek Universitas Nusantara PGRI Kediri \\ E-mail: hanafimbanaran@gmail.com ${ }^{1}$, \\ ardhimardiyantoindra@unpkediri.ac.id ${ }^{2}$,weda@unpkediri.ac.id ${ }^{3}$
}

Diterima: 14 Oktober 2017; Lolos: 17 November 2017; Dipublikasikan: 19 November 2017

\begin{abstract}
Abstrak
Tujuan yang ingin dicapai dalam penelitian ini adalah untuk mengetahui ada tidaknya pengaruh metode bermain bola tangan dan lempar tangkap bola terhadap efektifitas pembelajaran passing atas bolavoli pada siswa kelas XII TPHP SMK Putra Wilis Kecamatan Sendang Kabupaten Tulungagung. Penelitian ini menggunakan pendekatan Penelitian Tindakan Kelas (PTK) dengan subyek penelitian adalah siswa kelas XII TPHP SMK Putra Wilis Kecamatan Sendang Kabupaten Tulungagung. Penelitian dilaksanakan dalam dua siklus, menggunakan instrument berupa RPP, lembar observasi aktivitas siswa, lembar observasi aktivitas guru dan tes hasil belajar siswa. Kesimpulan hasil penelitian ini adalah 1) Melalui siklus tindakan pembelajaran dapat ditemukan langkahlangkah yang efektif penerapan metode bermain bola tangan dan lempar tangkap bola untuk meningkatkan efektifitas pembelajaran passing atas bolavoli melalui pengamatan aktivitas siswa diketahui kenaikannya mencapai 34,65\%, 2) Melalui siklus tindakan pembelajaran metode bermain bola tangan dan lempar tangkap bola terbukti dapat meningkatkan efektifitas pembelajaran passing atas bolavoli melalui pengamatan aktivitas guru kenaikannya mencapai $28,12 \%$, dan 3) Melalui siklus tindakan pembelajaran metode bermain bola tangan dan lempar tangkap bola terbukti dapat meningkatkan hasil belajar siswa mencapai 40,01\%.
\end{abstract}

Kata kunci: Metode Bermain, efektifitas pembelajaran, passing atas dan bolavoli.

\section{INFLUENCE OF THE METHOD OF PLAYING HANDBALL AND THROWING THE BALL TO THE EFFECTIVENESS OF PASSING LEARNING ON BOLAVOLI IN GRADE XII STUDENT OF TPHP SMK PUTRA WILIS SUBDISTRICT SENDANG TULUNGAGUNG REGENCY}

\begin{abstract}
The purpose of this research is to know whether or not there is influence of the method of playing handball and throwing the ball to the effectiveness of passing learning on bolavoli in grade XII student of TPHP SMK Putra Wilis Subdistrict Sendang Tulungagung Regency. This research using Classroom Action Research approach (PTK) with research subject of student of class XII TPHP SMK Putra Wilis Sub District Sendang Tulungagung Regency. The research was conducted in two cycles, using the instrument in the form of RPP, student activity

\begin{tabular}{cll}
\hline Email & hanafimbanaran@gmail.com & \\
& ardhimardiyantoindra@unpkediri.ac.id ${ }^{2}$ & @2017 UN PGRI Kediri \\
& weda@unpkediri.ac.id ${ }^{3}$ & p-ISSN: 2548-7833 \\
& e-ISSN: 2477-3379
\end{tabular}

No Handphone : 085740065428
\end{abstract}


Ridwan Hanafi ${ }^{1}$, Ardhi Mardiyanto Indra Purnomo ${ }^{2}$, Weda $^{3}$

Pengaruh Metode Bermain Bola Tangan dan Lempar Tangkap Bola Terhadap Efektifitas Pembelajaran Passing Atas Bolavoli Pada Kelas XII TPHP SMK Putra Wilis Kecamatan Sendang Kabupaten Tulungagung

observation sheet, teacher activity observation sheet and student learning result test. The conclusions of this reseacrh are 1) Through the learning action cycle can be found steps - the effective step of applying the method of playing handball and throwing the ball to improve the effectiveness of passing learning on the volleyball playing through the observation of student activity is known increase reaches $34.65 \%$, (2) Through the learning action cycle the method of playing handball and throwing the ball proven to improve the effectiveness of passing learning on the volleyball playing through observation of teacher activity increase reaches $28,12 \%$, and 3 ) Through the learning action cycle, the method of playing handball and throwing the ball is proven to improve student's learning achievement reach $40,01 \%$.

Keywords: Playing methods, effectiveness of learning, passing over and volleyball playing.

\section{PENDAHULUAN}

Bolavoli menjadi olahraga yang menyenangkan karena dapat beradaptasi dengan kondisi yang mungkin timbul didalamnya, dapat dimainkan dengan jumlah pemain dua orang dan permainan dengan jumlah enam orang. Olahraga bolavoli dapat dimainkan disegala bentuk lapangan seperti rumput, kayu, pasir, ataupun lantai buatan, serta dapat dilakukan di gedung.

Permainan bolavoli memiliki beberapa bentuk teknik dasar yang perlu dikuasai oleh seorang pemain. Menurut Nuril (2007: 20) "Dalam permainan bolavoli ada beberapa teknik dasar yang harus dikuasai". Teknik dasar permainan bolavoli terdiri dari atas service, passing, block, dan smash. Penguasaan teknik dasar sangat penting agar bisa bermain bolavoli dengan baik. Untuk mengusai teknik-teknik dasar tersebut diperlukan latihan-latihan teknik dasar secara terus menerus dan sungguh-sungguh supaya dapat menguasai teknik bolavoli itu dengan mudah. Selain itu, semakin marak pula dengan adanya pembinaan olahraga bolavoli seperti di lisensi-lisensi perusahaan, pemerintah dan juga di lembaga-lembaga pendidikan baik di Sekolah Dasar (SD), Sekolah Menengah Pertama (SMP), Sekolah Menengah Atas (SMA), Sekolah Menengah Kejuruan (SMK) maupun di Perguruan Tinggi. Menurut Mahendra (2003: 12) menjelaskan bahwa pendidikan jasmani merupakan proses pendidikan melalui aktivitas jasmani, pendidikan jasmani atau olahraga yang terpilih untuk mencapai tujuan pendidikan. Mahendra 
Ridwan Hanafi ${ }^{1}$, Ardhi Mardiyanto Indra Purnomo ${ }^{2}$, Weda $^{3}$

Pengaruh Metode Bermain Bola Tangan dan Lempar Tangkap Bola Terhadap Efektifitas Pembelajaran Passing Atas Bolavoli Pada Kelas XII TPHP SMK Putra Wilis Kecamatan Sendang Kabupaten Tulungagung

(2003: 13) menjelaskan bahwa tujuan pembelajaran pendidikan jasmani itu harus mencangkup block, dan smash. Penguasaan teknik dasar sangat penting agar bisa bermain bolavoli dengan baik. Untuk mengusai teknikteknik dasar tersebut diperlukan latihan- latihan teknik dasar secara terus menerus dan sungguh-sungguh supaya dapat menguasai teknik bolavoli itu dengan mudah. Selain itu, semakin marak pula dengan adanya pembinaan olahraga bolavoli seperti di lisensi-lisensi perusahaan, pemerintah dan juga di lembaga-lembaga pendidikan baik di Sekolah Dasar (SD), Sekolah Menengah Pertama (SMP), Sekolah Menengah Atas (SMA), Sekolah Menengah Kejuruan (SMK) maupun di Perguruan Tinggi.

Kondisi SMK Putra Wilis berlokasi di jalan Penampihan Kecamatan Sendang Kabupaten Tulungagung. SMK Putra Wilis merupakan SMK yang masuk dalam kategori sekolah perintis dalam hal kompetensi guru dalam mengajar. Mengingat SMK Putra Wilis merupakan sekolah perintis yaitu. Sekolah yang membutuhkan adanya pembaharuan ilmu di setiap bidang mata pelajaran. Sehingga SMK Putra Wilis selalu mengutamakan pelayanan yang terbaik kepada siswa - siswinya agar tujuan belajar mengajar dapat tercapai dengan baik.

Berdasarkan hasil obsevasi di lapangan ditemukan bahwa kemampuan passing atas pada siswa masih rendah. Proses pembelajaran olahraga masih tergolong masih monoton, biasanya setelah siswa jenuh yang dilakukan siswa untuk mengisi kejenuhan ialah bermain dengan teman sendiri seperti berlari dan berkejar-kejaran bahkan berbicara dengan teman sehingga membuat situasi pembelajaran tidak kondusif lagi.

Berpijak pada latar belakang masalah yang telah di uraikan diatas maka dapat diidentifikasi sebagai berikut:

1. Pembelajaran passing atas bovoli belum menunjukan hasil yang maksimal.

2. Minat siswa terhadap pebelajaran passing atas bolavoli yang masih rendah. 
Ridwan Hanafi ${ }^{1}$, Ardhi Mardiyanto Indra Purnomo ${ }^{2}$, Weda $^{3}$

Pengaruh Metode Bermain Bola Tangan dan Lempar Tangkap Bola Terhadap Efektifitas Pembelajaran Passing Atas Bolavoli Pada Kelas XII TPHP SMK Putra Wilis Kecamatan Sendang Kabupaten Tulungagung

3. Belum adanya metode pembelajaran yang pakem sehingga proses belajar mengajar siswa menjadi monoton.

4. Kemampuan teknik dasar passing atas bolavoli masih kurang.

5. Belum diketahuinya pengaruh metode bermain bola tangan dan lempar tangkap bola terhadap efektifitas pembelajaran passing atas bolavoli pada kelas XII TPHP SMK Putra Wilis Kecamatan Sendang Kabupaten Tulungagung.

Berdasarkan latar belakang masalah dan identifikasi masalah pada peneliti ini perlu dirumuskan permasalahanya. Adapun perumusan masalah dalam penelitian ini adalah "Adakah Pengaruh Metode Bermain bermain bola tangan dan lempar tangkap bola terhadap efektifitas pembelajaran passing atas bolavoli pada kelas XII TPHP SMK Putra Wilis Kecamatan Sendang Kabupaten Tulungagung ?".

\section{METODE PENELITIAN}

Penelitian ini menggunakan rancangan Penelitian Tindakan Kelas (PTK) kolaboratif, yaitu PTK. Berdasarkan berbagai sumber seperti Mettetal (2003), Penelitian Tindakan Kelas (PTK) atau classroom action research (CAR) didefinisikan sebagai penelitian yang dilakukan oleh guru di dalam kelasnya sendiri melalui refleksi diri, dengan tujuan untuk memperbaiki kinerjanya sebagai guru, sehingga hasil belajar siswa menjadi meningkat. Dalam model penelitian ini, penulis (guru) bertindak sebagai pengamat (observer) sekaligus sebagai patisipan, yang melibatkan teman sejawat sebagai kolabolator.

Model Penelitian Tindakan Kelas (PTK) yang digunakan adalah berdasarkan pada PTK model Kemmi's dan Taggart (dalam Sa'dun, 2009). Rancangan PTK model ini terdiri dari 4 tahapan dengan 2 siklus. Masing-masing siklus terdiri dari 4 tahap, yaitu perencanaan tindakan, pelaksanann tindakan, tahap pengamatan, tahap refleksi.

Data yang akan diambil dalam penelitian ini adalah data aktivitas guru, data aktivitas siswa, dan data hasil belajar. Teknik pengumpulan data dalam penelitian ini antara lain. 1) Observasi ini dilakukan oleh 
Ridwan Hanafi ${ }^{1}$, Ardhi Mardiyanto Indra Purnomo ${ }^{2}$, Weda $^{3}$

Pengaruh Metode Bermain Bola Tangan dan Lempar Tangkap Bola Terhadap Efektifitas Pembelajaran Passing Atas Bolavoli Pada Kelas XII TPHP SMK Putra Wilis Kecamatan Sendang Kabupaten Tulungagung

observer (guru dan teman sejawat) dengan menggunakan pedoman pengamatan berupa format atau daftar cek; 2) Angket, diberikan sebagai bahan evaluasi secara kualitatif terhadap respon siswa terhadap penerapan metode bermain bola tangan dan lempar tangkap bola; 3) Tes, adalah serentetan atau latihan yang digunakan untuk mengukur ketrampilan, pengetahuan, sikap intelegensi, kemampuan atau bakat yang dimiliki individu atau kelompok.

Jenis data yang diperlukan dalam penelitian ini adalah, 1) Data tentang banyaknya passing atas bolavoli dalam waktu 60 detik yang dilakukan siswa - siswi pada kelas XII TPHP SMK Putra Wilis Sendang Kabupaten Tulungagung Tahun Pelajaran 2016-2017; 2) Data tentang pelaksanaan pembelajaran pada saat tahap tindakan dari PTK dilaksanakan.

Teknik dan Instrumen yang digunakan dalam penelitian ini adalah data tentang banyaknya passing atas bolavoli dalam waktu 60 detik yang dilakukan siswa - siswi padakelas XII TPHP SMK Putra Wilis Sendang Kabupaten Tulungagung dikumpulkan dengan teknik hasil belajar. Penilaian hasil adalah hasil yang dicapai dalam bentuk angka-angka atau skor setelah diberikan tes hasil belajar pada setiap ahkir pembelajaran. Nilai yang diperoleh siswa menjadi acuan untuk melihat penguasaan siswa dalam menerima materi pelajaran. (Dimyati dan Mudjiono, 2006). Dengan menggunakan instrumen penilaian hasil sebagai berikut :

1) Subjek yang dinilai : Siswa- siswi Kelas XII TPHP SMK Putra Wilis Sendang Kabupaten Tulungagung

2) Kemampuan yang dinilai: banyaknya passing atas bolavoli dalam waktu 60 detik.

3) Indikator: Melakukan passing atas bolavoli dalam waktu 60 detik dengan baik dan benar.

4) Teknik penilaian : Penilain hasil belajar

5) Prosedur tes passing atas: a) Guru menyiapkan media dan alat yang diperlukan seperti bola voli, lapangan bola voli, peluit dan stopwatch.

b) Guru menjelaskan langkah-langkah permainan yang akan SPORTIF, 3 (2) 2017 | 230-239 
Ridwan Hanafi ${ }^{1}$, Ardhi Mardiyanto Indra Purnomo ${ }^{2}$, Weda $^{3}$

Pengaruh Metode Bermain Bola Tangan dan Lempar Tangkap Bola Terhadap Efektifitas Pembelajaran Passing Atas Bolavoli Pada Kelas XII TPHP SMK Putra Wilis Kecamatan Sendang Kabupaten Tulungagung

dipraktekan. c) Siswa membentuk kelompok yaitu dengan dibagi 2 kelompok yaitu kelompok 1 dan 2. Satu kelompok berisi 7 siswa tergantung banyaknya siswa. d) Siswa anggota kelompok 1 atau pertama memegang bolavoli dengan aturan satu siswa memegang satu bolavoli. e) Untuk kelompok 2 atau kelompok berikutnya ditugaskan untuk menghitung berapa banyak siswa melakukan passing atas bolavoli dengan baik dan benar sesuai dengan petunjuk guru. f) Jika siswa sudah siap maka guru akan meniupkan bunyi peluitnya dimana aba-aba tes passing atas akan segera dimulai dengan waktu 60 detik. g) Jika mendengar bunyi peluit lagi itu menandakan tes passing atas sudah selesai. h) Siswa yang ditugaskan menghitung banyaknya passing atas tadi langsung melaporkan hasilnya kepada guru. Dan dilakukan terus menerus sampai siswa melakukan tes semua. i) Jika tes passing atas sudah selesai. Guru segera mengamati dan merefleksikan hasil data yang sudah didapat tersebut.

Data yang dianalisis yaitu hasil yang diperoleh pada pelaksanaan tes passing atas bolavoli. Analisis data yang digunakan oleh peneliti yaitu hasil penelitian pada setiap siklus. Peneliti membuat perbandingan persentase kemampuan peserta didik sebelum tindakan dan sesudah tindakan dengan metode bermain bola tangan dan lempar tangkap bola. Adapun rumus yang digunakan untuk mencari persentase dalam penelitian ini adalah sebagai berikut:

Analisis data materi passing atas bolavoli dan hasil belajar siswa diperoleh dari hasil tes siswa. Penentuan ketuntasan belajar siswa dapat dihitung menggunakan rumus:

$$
N=\frac{\text { Jumlah siswa tuntas }}{\text { Jumlah seluruh siswa }} \times 100 \%
$$

Keterangan:

$\mathrm{N}=$ Porsentase ketuntasan dalam Arikunto, (2006: 243)

Analisis lembar observasi digunakan rumus: 
Ridwan Hanafi ${ }^{1}$, Ardhi Mardiyanto Indra Purnomo ${ }^{2}$, Weda $^{3}$

Pengaruh Metode Bermain Bola Tangan dan Lempar Tangkap Bola Terhadap Efektifitas Pembelajaran Passing Atas Bolavoli Pada Kelas XII TPHP SMK Putra Wilis Kecamatan Sendang Kabupaten Tulungagung

$$
P=\frac{n}{N} \times 100 \%
$$

Keterangan:

$\mathrm{P}=$ Prosentase frekuensi kejadian yang muncul

$\mathrm{n}=$ Banyaknya aktivitas siswa yang muncul

$\mathrm{N}=$ Jumlah aktivitas keseluruhan

(Arikunto, 2006: 129)

Tabel 1 Kriteria Keberhasilan Peserta didik

\begin{tabular}{cc}
\hline Presentase (\%) & Kategori \\
\hline $80-100$ & Sangat Baik \\
\hline $60-80$ & Baik \\
\hline $40-60$ & Cukup \\
\hline $20-40$ & Kurang Baik \\
\hline $0-20$ & Tidak baik \\
\hline
\end{tabular}

(Sumber: Arikunto, 2010: 107)

Membandingkan ketuntasan belajar (jumlah presentase peserta didik yang mendapat nilai dengan kategori baik dan sangat baik) antara waktu sebelum tindakan dilakukan, dengan setelah dilakukan tindakan siklus I sampai tindakan siklus II dengan menggukan metode bermain bola tangan dan lempar tangkap bola standar minimal peningkatan kemampuan individu khususnya pada kemampuan passing atas bolavoli dengan baik dan benar adalah apabila peserta didik mampu mencapai nilai minimal baik, artinya peserta didik sudah mampu meningkatkan kemampuan passing atas bolavoli dengan baik dan benar. Kriteria keberhasilan tindakan apabila terjadinya kenaikan ketuntasan belajar (setelah tindakan siklus II ketuntasan belajar mencapai sekurangkurangnya $75 \%)$.

\section{HASIL DAN PEMBAHASAN}

Pada pembahasan hasil penelitian ini akan di analisis peningkatan aktivitas guru, aktivitas siswa dan hasil belajar siswa dalam pembelajaran siklus I sampai siklus II dengan menggunakan metode bermain bola tangan dan lempar tangkap bola. 
Ridwan Hanafi ${ }^{1}$, Ardhi Mardiyanto Indra Purnomo ${ }^{2}$, Weda $^{3}$

Pengaruh Metode Bermain Bola Tangan dan Lempar Tangkap Bola Terhadap Efektifitas Pembelajaran Passing Atas Bolavoli Pada Kelas XII TPHP SMK Putra Wilis Kecamatan Sendang Kabupaten Tulungagung

Dari deskripsi data hasil penelitian dapat dijelaskan lebih lanjut hal - hal sebagai berikut:

Tabel 2 Perbandingan aktivitas guru siklus I dan II

\begin{tabular}{cccc}
\hline Aspek Peningkatan & Siklus 1 & Siklus II & Keterangan \\
\hline Rata-rata aktivitas guru & $62,5 \%$ & $90,62 \%$ & Meningkat \\
\hline
\end{tabular}
(Sumber: Data penelitian)

Berdasarkan hasil observasi yang dilakukan oleh guru pada siklus I dan siklus II dapat dijelaskan bahwa pada siklus I persentase hasil observasi yang didapatkan yaitu sebesar $62,5 \%$, kemudian pada siklus II persentase yang didapatkan yaitu 90,62\%, jadi terdapat kenaikan antara fase dari siklus I menuju siklus II.

Berikut ini adalah diagaram perbandingan aktivitas guru yang terjadi antara siklus I dan siklus II:

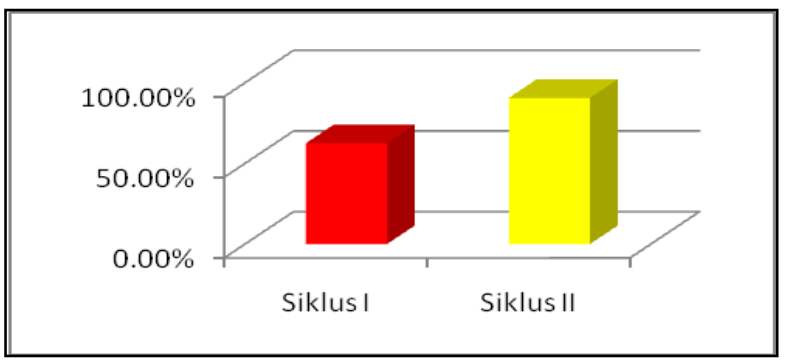

Gambar 1 Diagram Perbandingan Aktivitas Guru

Berdasarkan diagram observasi aktivitas guru dari siklus I dan II setelah diberi tindakan pengamatan dapat disimpulkan kenaikan mencapai $28,12 \%$.

Tabel 3 Perbandingan aktivitas siswa siklus I dan II

\begin{tabular}{cccc}
\hline Aspek Peningkatan & Siklus I & Siklus II & Keterangan \\
\hline Rata-rata aktivitas siswa & $49,1 \%$ & $83,75 \%$ & Meningkat \\
\hline
\end{tabular}

(Sumber: Data penelitian)

Pada bagian aktivitas siswa hasil observasi yang didapat pada siklus I persentase nya yaitu 49,1\%, kemudian pada siklus II persentase yang didapatkan sebesar $83,75 \%$, yang dimana terdapat kenaikan yang sangat berarti dari siklus I ke siklus II.

Berikut ini adalah diagaram perbandingan aktivitas siswa yang terjadi antara siklus I dan siklus II : 
Ridwan Hanafi ${ }^{1}$, Ardhi Mardiyanto Indra Purnomo ${ }^{2}$, Weda $^{3}$

Pengaruh Metode Bermain Bola Tangan dan Lempar Tangkap Bola Terhadap Efektifitas Pembelajaran Passing Atas Bolavoli Pada Kelas XII TPHP SMK Putra Wilis Kecamatan Sendang Kabupaten Tulungagung

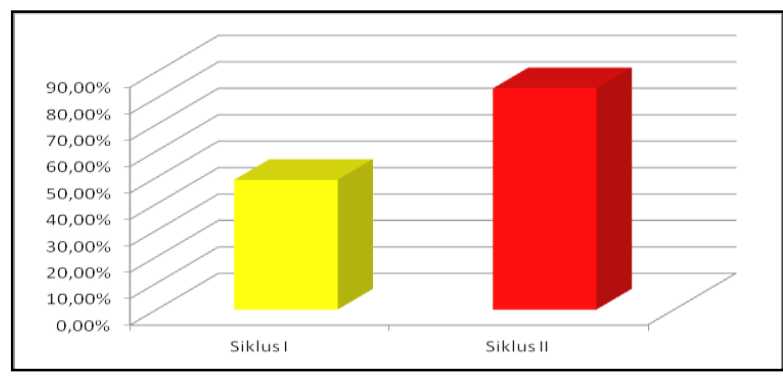

Gambar 2 Diagram Perbandingan Aktivitas Siswa

Berdasarkan diagaram observasi aktivitas siswa dapat disimpulkan setelah diberi tindakan pengamatan dari siklus I dan II kenaikan mencapai 34,65\%.

Tabel 4 Perbandingan hasil belajar siswa siklus I dan II

\begin{tabular}{llccc}
\hline \multicolumn{2}{c}{ Aspek peningkatan } & Siklus I & Siklus II & Keterangan \\
\hline Respon siswa dalam penerapan & & & \\
metode bermain bola tangan dan & $59,9 \%$ & $100 \%$ & Meningkat \\
lempar tangkap bola pada & & & \\
pembelajaran passing atas bolavoli & & & \\
\hline
\end{tabular}
(Sumber: Data penelitian)

Berikut ini adalah diagaram perbandingan hasil belajar siswa yang terjadi antara siklus I dan siklus II:

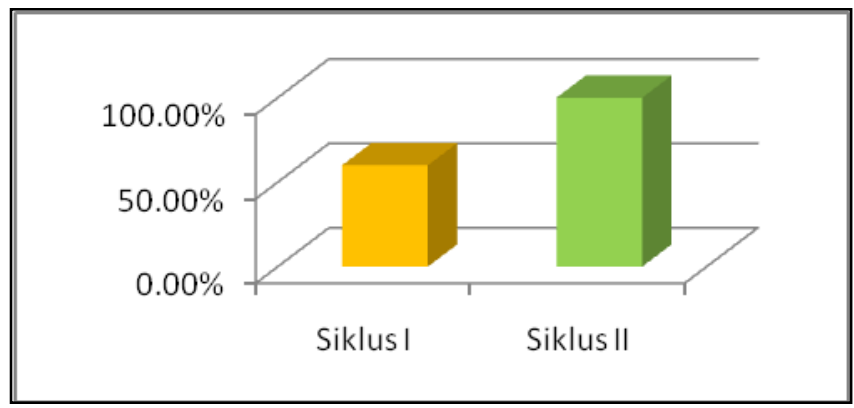

Gambar 3 Diagram Perbandingan Hasil Belajar Siswa

Berdasarkan data belajar siswa dapat disimpulkan bahwa sebelum dan sesudah diberi tindakan maka dari siklus I sampai II diketahui kenaikan hasil belajar siswa mencapai 40,01\%. 
Ridwan Hanafi ${ }^{1}$, Ardhi Mardiyanto Indra Purnomo ${ }^{2}$, Weda $^{3}$

Pengaruh Metode Bermain Bola Tangan dan Lempar Tangkap Bola Terhadap Efektifitas Pembelajaran Passing Atas Bolavoli Pada Kelas XII TPHP SMK Putra Wilis Kecamatan Sendang Kabupaten Tulungagung

\section{KESIMPULAN}

Berdasarkan penelitian yang telah dilakukan dapat diambil kesimpulan sebagai berikut: "Ada pengaruh metode bermain bola tangan dan lempar tangkap bola terhadap efektifitas pembelajaran passing atas bolavoli pada kelas XII TPHP SMK Putra Wilis dibuktikan dengan peningkatan tes hasil belajar tuntas siswa, lembar observasi aktifitas siswa dan lembar observasi aktifitas guru".

\section{DAFTAR PUSTAKA}

Akbar, Sa'dun. 2009. Penelitian Tindakan Kelas: Filosofi Metodologi \& Implementasi. Yogyakarta: Cipta Media Aksara.

Arikunto, Suharsimi. 2010. Penelitian Tindakan Kelas. Jakarta: PT. Rineka Cipta.

Arikunto, Suharsimi. 2006. Prosedur Penelitian Suatu Pendekatan Praktek. Jakarta: Rineka Cipta.

Dimyati dan Mujiono. 2002. Belajar dan Pembelajaran. Jakarta: PT Rineka Cipta.

Darmawan, Agung R. 2012. Pengaruh Metode Bermain Terhadap Kemampuan Passing Atas Bolavoli Peserta Ekstrakulikuler di SMA $N 1$ Bantul. Skripsi. Yogyakarta: FIK UNY

Kemmi's dan Taggart. 1988. The Action Research Planner. Victoria: eakin University.

Mahendra, Agus. 2000. Bola Tangan. Bandung: Departemen Pendidikan Nasional.

Mahendra, Agus. 2003. Falsafah Pendidikan Jasmani. Jakarta: Direktorat Pendidikan Luar Biasa.

Nuril, Ahmadi. 2007. Panduan Olahraga Bolavoli. Solo: Eka Pustaka.

PBVSI. 2002. Bolavoli. http://id.Wikipedia.org/wiki/Bola_voli. Diakses 30 Januari 2017. 